\title{
GOING VIRTUAL IN THE EUROPEAN BIOPHARMACEUTICAL INDUSTRY: CONDUCTORS AND OXPECKERS MAKE IT
}

\author{
Valérie Sabatier ${ }^{1,4}$, Vincent Mangematin ${ }^{1,2,3}$, Tristan Rousselle ${ }^{4}$ \\ ${ }^{1}$ Univ. Grenoble 2, UMR 1215 GAEL, F-38000 Grenoble, FRANCE \\ ${ }^{2}$ INRA, UMR 1215 GAEL, F-38000 Grenoble, FRANCE \\ ${ }^{3}$ Grenoble Ecole de Management, F-38000 Grenoble, FRANCE \\ ${ }^{4}$ Protein'eXpert, F-38000 Grenoble, FRANCE \\ valeriesabatier@proteinexpert.com,vincent@grenoble.inra.f,tristanrousselle@proteinexpert.com
}

\begin{abstract}
In the sector of biopharmaceuticals, the dominant business model remains the one of big pharmas: the vertical integration. However we currently observe in the European biotechnology industry the emergence of new business models. This article studies in particular the cases of an orchestra firm and a repurposing firm, both virtual all along the value chain of drugs.

It shows that being virtual is possible in the European biopharmaceutical industry. Small virtual firms are able to play the role of hub firms in networks. These organizations, despite their small size and limited funding, manage to build networks with academics and industrials, long-run partnerships, and, icing on the cake: the drug development cost should be much lower than big pharmas'.
\end{abstract}

\section{INTRODUCTION}

Biopharmaceuticals are drugs derived from biotech research, in contrast with the pharmaceutical industry which is traditionally based on chemistry development. The dominant design is the vertical integration. It is comparable with the organization of the computer industry from the mid eighties (Magretta 1998).

The biotech industry, born in the eighties, reaches today its teenage years. Original organizations appear with clever business models, alternative to the vertical integration. Business Models are pictures of a company that show the way the firm organizes its business along the value chain in order to create and capture value. A value chain is "the linked set of value creating activities all the way through from basic raw material sources for component suppliers to the ultimate end-use product delivered into the final consumer's hands" (Govindarajan V. and Gupta A.K. 2001). Regarding drugs the value chain involves four main consecutive steps leading to the market: research and drug discovery, preclinical studies (animal tests), phase I and II (early human clinical trials) and phase III trials (large human tests). Along this value chain there are three types of actors: academics, pharmas and biotechs. In a global vision academics are focused on the first link for fundamental research and drug discovery; pharmas are present at every step and especially on the last links (phase III and market); most of biotech firms are positioned on the first links of the chain and manage very well the early phases of drug development (see figure 1). 


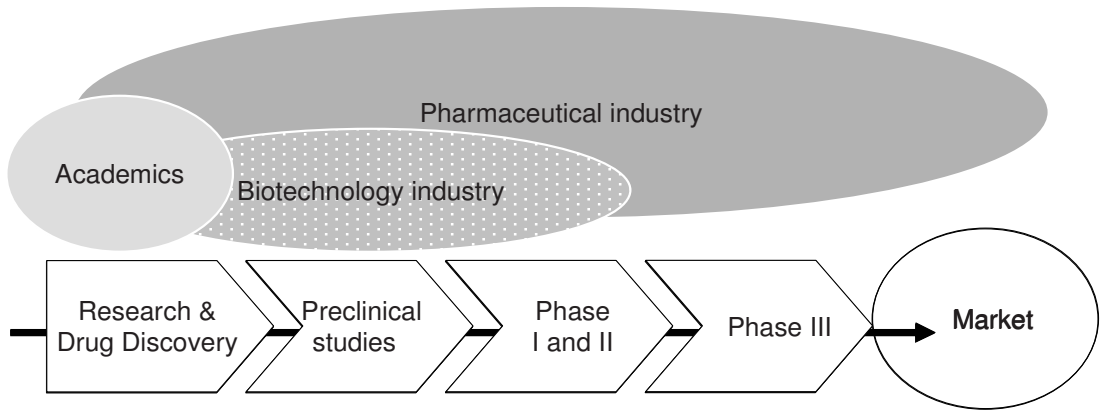

Figure 1: The value chain of drug development: technological steps and main actors.

The value chain of biopharmaceuticals is about 10 years and requires huge investments. The development cost for a new medicine is about US\$ 800 million (DiMasi J.A., Hansen R.W. et al. 2003) and US\$1.2 billion (DiMasi J. and Grabowski H.G. 2007) for a biopharmaceutical. However these results have to be considered with caution because data come from American large pharmas and four big international biotechs. The business model of all these firms is the full integration: they have internalized all the development steps.

Most of biotech firms born in the eighties were start-ups with a product in their pipeline or a service to sell. There were two main business models: the business model of the product developed in-house for early stage and the business model of the technology platform: a good expertise sold as services.

Focusing on business models we observe that the product model should give rise to several business models which appear since 2000 and by which biotech firms mimic the integrated model. Companies try to cover all the value chain and develop a pipeline of drugs. Despite the fact that fundings are much lower than cash flows available in the pharmaceutical industry to support drug development, some small biotechs have made their way up thanks to reticular organizations: they cover the value chain with a network of partners and suppliers. These firms by themselves do not have real laboratories, manufacturing capabilities or other usual departments of firms; they are virtual. It raises many questions: How do they organize themselves? How do they manage their network? What are the relationships between the actors? How is intellectual property managed? How is value created? How is value captured? Are these virtual firms more efficient than big pharmas? Is the cost of drug development reduced?

To answer these questions two firms that manage pretty well the mimicry of the business model of full integration have been studied: an orchestra firm and a repurposing firm. After a brief presentation of the methodology and the research positioning in the theoretical field, both cases will be detailed. Last part of the article is dedicated to a discussion and a conclusion.

\section{METHODOLOGY}

This research strategy focuses on understanding the dynamics present within single settings. Therefore the qualitative approach with case studies appears to be the more 
suitable (Eisenhardt K. 1989). The objective is to detect, characterize and describe new forms of organizations. The aim is not to generalize what is observed and two organizations are chosen precisely because they are very specific: they allow to gain certain insights that other organizations would not be able to provide (Siggelkow N. 2007). In order to determine a choice of sample, an exploratory study is done with opinion leaders in the European biotechnology industry. It includes the scientific director of a French international competitive cluster, the European vice president of one of the biggest international biotech firms and several CEOs of European biotech SMEs specialized in biopharmaceuticals. They give the trends of biotechnology sector and how they anticipate the future business of drugs. This global view is completed with the monitoring of technical and economical issues of the biopharmaceutical industry. A Chief Executing Officer of a biotech firm is involved in the research. He is interested in the problematic and allows access to the firms targeted. He acts as a trust facilitator (Mesquita L.F. 2007). He takes part in the first step of the study: the meetings with the main founders of the chosen firms. At that moment researchers are only lightly informed about the firms. The trust facilitator is there to observe and point out subjects that could have unfortunately been forgotten. Each interview lasts at least for two hours and depicts the global picture of the firms and their business models. A high level of confidentiality is assured to have access to strategic information.

The second phase is dedicated to documents analyses. Internal sources are crossed with documents found on specialized press and websites. Special attention is paid to websites when the company is not public: the repurposing firm is financed by venture capitalists and informs them directly. So the website is principally a showcase. On the opposite, SEC reports and a lot of public information are available for the European orchestra firm since it is quoted on the NASDAQ.

The third phase is the moment of deep interviews. Regarding the orchestra firm the CEO, the CSO (Chief Scientific Officer) and the CFO (Chief Financial Officer) are interviewed and for the repurposing firm it is the CEO, the CFO and the COO (Chief Operating Officer). Each individual interview lasts for one hour and half. Notes are taken during interviews. Then an oral report is recorded at the very end of the visit in order to remind the maximum of information as well as opinions and impressions. Finally longs and rich monographs are written with every detail and information. In conclusion all arguments are directly extracted from raw material.

\section{LITERATURE REVIEW}

The research question has its origin in the concept of hub firm. Dhanaraj and Parkhe (2006) explain that hub firms orchestrate network activities to ensure creation and extraction of value created among innovation networks. A hub firm is "one that possesses prominence (Wasserman \& Galaskiewicz, 1994) and power (Brass \& Burkhardt, 1993) gained through individual attributes and a central position in the network structure, and that uses its prominence and power to perform a leadership role in pulling together the dispersed resources and capabilities of network members" (Dhanaraj C. and Parkhe A. 2006). They study hub firms in networks that are loosely coupled coalitions (Provan K.G. 1983) as it is the case in biotechnology field. On Dhanaraj and Parkhe assumption a hub firm increases network innovation 
output if it manages to organize good knowledge mobility and the right innovation appropriation in accordance with the participation of each of actors. This outstanding article gives to the present research subject a strong support: a good framework and an invitation to study the concept in small firms. The hub firm, conceptualized such as they do, is a big firm. The same review can be done for the concepts of flagship firm (Rugman A. and D'Cruz J. 1997) or central firms (Lorenzoni G. and Baden-Fuller C. 1995). The orchestrator of the network is always seen as a big company. So we will look from a practical point of view if a small firm can play the role of the hub firm.

\section{Proposition 1: A small firm can play the role of hub firm.}

The perspective of drug development implies that a company masters all the technological steps. For a small firm it appears impossible: it requires a lot of people, laboratories, competences, from early discovery to market production. The only issue is to outsource a maximum to a network of partners, allies or suppliers, in other words, becoming a virtual firm. Thus, being in a network will bring all the competences as well as facilities needed. The term virtual firm is often associated to a firm doing business by internet or utilizing electronic capabilities that make it possible to respond and collaborate in more flexible manners and to organize activities in ways that were not previously possible (Cooper W. and Muench M. 2000), for example e-business development is technology based. Although the firms studied are not e-business firms it is true that electronic capabilities as well as emails and internet tools will help connecting people in the network. Furthermore virtual firms have sometimes been considered in the literature like a permanent network of independent organizations (Weisenfeld U., Reeves J.C. et al. 2001). The term virtual firm will define here a small biotech firm, outsourcing most of its activities to an array of partners (Chesbrough H.W. and Teece D.J. 1996). We will examine if a virtual firm can play the role of hub firm along the value chain of drugs.

\section{Proposition 2: A small virtual firm can be the hub firm of a network.}

If a virtual firm manages the development of a drug with a network of partners the firm should get the best of competences in every domain and avoid the cost of learning. A virtual firm should be far superior to the monolithic and pyramid-shaped corporate structure because it takes technologies and skills in core business of each company of the network (Bigras, 2002). Advantages of virtual firms result from the "networked intelligence" they enable among the flexible components that comprise them (Sawhney M. and Parikh D. 2001). In addition, other costs can be saved because there are no heavy investments for laboratories or manufacturing capabilities and few costs of staff. Next, a good orchestration should leads to good link between the phases and time should be shortened. So we state the hypothesis that a virtual firm developing drugs is value creator because of more flexibility, lower fixed costs and better integration of the different phases.

\section{Proposition 3: The cost of a biopharmaceutical developed by a virtual firm orchestrating a network will be lower than the cost of a (bio)-pharmaceutical developed by a big pharma.}

These hypotheses are tested using the framework of the business model: structure of the firms (size, age, financing, and governance), links with the other firms of the 
network (type of relationships, innovation appropriation with intellectual property, information flow, risk sharing, and opportunism), points of value creation (development of the drug, scientific process, management and capitalization of competences) and process of value capture (revenue model, time and cost savings).

\section{THE ORCHESTRA FIRM: CASE STUDY OF EMICS}

The orchestra firm Emics is product based: it develops a prophylactic vaccine. Emics is a small biotech company based today in Switzerland, made up of three persons: a CEO, a CSO and a CFO. The scientific advisory board is also made up of three scientists and experts in the therapeutic domain. The business model of Emics is the orchestrator model: it develops a drug along the value chain orchestrating a network of partners and suppliers. Emics does not have any laboratory or factory, it is a virtual enterprise.

Emics was founded in France in 1990's. In 2000 it goes through a reverse merger with an American company listed on the NASDAQ. After a series of difficulties a new management team takes over the control in 2003. At that time the firm is already listed on OTCBB ${ }^{1}$. Although it is public there is no liquidity: stocks are not fluid and there is no reserve. From the very beginning, Emics does not have any sales or revenue because it does not sell product or service. The company runs thanks to the contribution of some private investors. The funds are invested in the development of the company's drug pipeline.

The management team is rather experienced. The CEO was an independent business consultant for years. He worked for a firm doing business in the medical field. However he does not have a strong specialization in biotech industry. The CSO worked previously in an academic laboratory within the same therapeutic field where he gains strong recognition. The CFO worked as auditor and consultant in European banks. Since 1991 he evolves professionally in the biotech sector. This "dream team" met when they were all shareholders of Emics. They decided together to save the firm which situation was going from bad to worse. In 2003 they did a kind of putsch and took the control of the company. Emics was already virtual, working with subcontractors to develop drug candidates. The team realigned the scientific project and chose to focus on one prophylactic vaccine, against a worldwide infectious disease.

Since 2003, all efforts are done in order to develop the vaccinal approach. However, Emics had serious financial difficulties. They should have ended up but a providential investor retrieved the situation. In a way, the pathology helped them: it is a worldwide and mortal infectious disease that anyone can catch and no vaccine exists. Investors as well as some of their suppliers were sensitive to the ideological aim.

The vaccine is developed within a network of twelve partners: two strategic industrial partners and two strategic academic partners, plus five industrials and three academics suppliers. A strategic partner is a partner involved in the developed of the vaccine; he exercises a major influence in the project, without him innovation is impossible. The upstream research is done with the academic strategic partners and crucial development steps are done with strategic industrial partners. The others 
are service or product suppliers: they are doing the preclinical trials; they produce a piece of the vaccine, etc. (see figure 2).

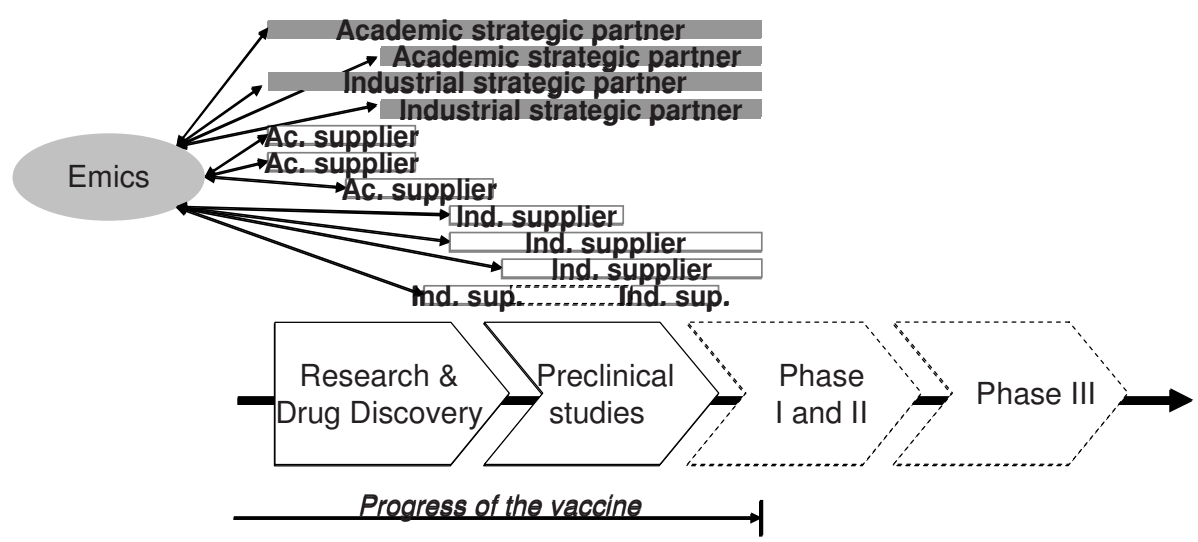

Figure 2: The network managed by Emics and position of actors on the value chain.

Emics interacts with its partners on a long run perspective. But surprisingly relations are dyadic with every member of the network: there is no contact between the different firms involved in the process of the drug development. It really looks like an orchestra: the conductor shapes the process the players do. Each musician plays his music and although he knows the others are also working, he obeys to the conductor instructions. He does not need to know exactly what the others do as long as he follows the conductor. The orchestra firm selects and distributes information. Emics gives almost all information to the strategic partners but they do not have a central position: like the others they are only in touch with Emics. The role of the chief scientific officer is fundamental because he coordinates and controls every technological step. He is the only in Emics that can follow the vaccine development and define medical strategies.

Regarding intellectual property Emics owns the patents linked to the vaccine because it was in the package of the firm when the team took it over. But a vaccine includes different and specific technologies. When a strategic partner develops a critical technology for the vaccine, IP is shared with him. The risk is also divided: when Emics had financial problems its strategic partners accepted to be paid with stocks and delays. This is even the case with one academic collaborator. This is not the case with the suppliers like the contract research organization doing the animal trials: Emics pays in time under the exact terms of the contract.

Value created by Emics comes from many sources. Obviously, the fact that there is no physical structure leads to weak investments. Next, as the development is only the CSO's will, decisions are taken quickly. The phases of development are going one after the other very rapidly. They are doing a lot of savings with the scientific strategy because reducing time and cost is a very important objective: they are always on a tight budget. As an example, they watch very carefully at the scientific results and as soon as one is not concluding they stop it. On the opposite, big pharmas test simultaneously several strategies and stop it only when the protocol is over. Next, the ability to choose partners and suppliers is value creator: Emics gets the best of competences in every domain. Afterwards, another point of value creation is the way they manage the network: long run relationship, co-development 
including risk and IP sharing with strategic partners. These long-run relationships and the sensibility of the academic and biotech SMEs partners for the vocation of the vaccine led to low costs: they sometimes behave like philanthropists. In four years of development Emics spent 7.945 million US\$. This is ten times lower than what big pharmas announce from preclinical studies to phase I clinical trial for drugs (see DiMasi et al. 2003). In terms of revenue model Emics forecast a hypothetical exit of the project after phase II. Phase III clinical trials, especially for vaccine development, are huge, longs and expensive. Big pharmas are used to these kinds of trials and this is why there are predominant on the end steps of the value chain. They have competences and cash flows available. Thus Emics hopes for finding a partner or a buyer to lead end clinical trials.

However everything is not so easy for Emics. The management team has difficulties to face the problem of solvability and credibility as an orchestra firm. Because of its size and its limited financial capabilities Emics may have a low bargaining power in front of a supplier but also in the scientific field. The scientific approach of the vaccine is very peculiar and difficult to use to convince new partners. For example they could not convince a big pharma that their approach was good.

Finally, Emics will start first human trials very soon. Their financial situation is in order. Indeed and after a quite long period of hard days, their product recently obtained very good results in preclinical studies on macaques. So investors are more upbeat and support them. Emics keep its way of working. Like a conductor, it indicates to each musician how to play in unison, sending signals to each one of them and being the center of the information flow.

\section{THE REPURPOSING FIRM: CASE STUDY OF OPHSMART}

OphSmart is a product based firm that develops drugs. It is a small biotech company based in France with an office in USA. OphSmart is made up of thirty persons, including seventeen scientists. The company is governed by a management team, a scientific advisory board and a board of directors. Everybody is located in the offices in France except a person of the management team based in USA.

The business model is twofold: OphSmart pursue some in-house and very upstream research in a long run perspective; and it develops repurposed molecules. The repurposing consists of taking a molecule in development or on the market for another therapeutic domain and positioning it on a new therapeutic domain. In other words a firm takes a molecule outside and intended for example for regenerative medicine and then develops it in another application like Alzheimer disease: the molecule is repurposed. This is what OphSmart did for four products obtained from other companies. This small firm has 4 repurposed drugs in development and 4 molecules in research: it is exceptional for such a small team. OphSmart outsources almost all activities along the drug development chain. The repurposing is the main activity of OphSmart because in-house research requires a small team and most of the company is mobilized in the business of repurposing.

The CEO, founder of OphSmart, has a strong experience in the biotech industry as a scientist, general manager and investor. In 1997 he met an academic, major actor in the therapeutic domain they now both work in. At the end of 2004 they 
thought that time had come to create OphSmart. They came across another fellow, a well-known business developer. The hardcore of OphSmart was ready and the firm has been founded end of 2005. The business developer is now Chief Operating Officer (COO) and the academic is chairman of the scientific advisory board. The management team is made up of nine persons: the CEO, the COO plus a chief medical officer, a chief financial officer (CFO), a chief business officer, a global project leader, a person in charge of the preclinical development, the administration and finance director and the head of scientific operations. Specifically there is no chief scientific officer. This activity is shared between the chief medical officer, the head of preclinical development and the head of scientific operations.

At the first financial round OphSmart rises more than 20 million Euros. The firm is supported by five investors, venture capitalists. Funds are found quite easily because the business model is very attractive and promises high return on investment on a short run ( 3 to 5 years) thanks to the repurposing and an in-house research very light in terms of cash burn.

OphSmart's management team is aware of clinical trials in progress in pharmaceutical or biopharmaceutical industry thanks to the large network of contacts they have. This is how they find the molecules to be repurposed.

The network of OphSmart is stable and made of an academic laboratory and many industrial suppliers and partners. The links with the academic partner are very strong. This partner is involved in both processes: repurposing and in-house research. It is the only strategic partner. OphSmart has got a big network of industrials and cultivates redundancy. For example they work regularly with seven firms for the formulation, five for the toxicity of the drug and six for the production of clinical batches. It allows them to have the core competence of each firm but also to go quickly and cheaply through the drug development: they choose the partner in accordance with the competences, the availability at the very moment they need and the price.

The relationships with suppliers are based on the long run. OphSmart manages and regulate the information flow. Like in the previous case relations are dyadic and OphSmart is the central actor of the network (figure 3).

The issue of intellectual property is more subtle because in the repurposing model the molecule is already patented. When a company files a patent application, the company specifies the therapeutic domain. In the repurposing the therapeutic domain is different. So OphSmart patents the same molecule but for another therapeutic domain. Then they negotiate a use-of-patent with the original owner because patents are linked. They pay milestones and royalties to the original owners. Smartly OphSmart convinced the Pharmas to back load most of payments because they were a small biotech. The Pharmas accepted as it was an unexpected outcome for them. They did not forecast a repurposing of their molecule. Among its network of partners, OphSmart shares IP when a critical technological development has to be done but it is rare and OphSmart keeps IP as much as possible. 


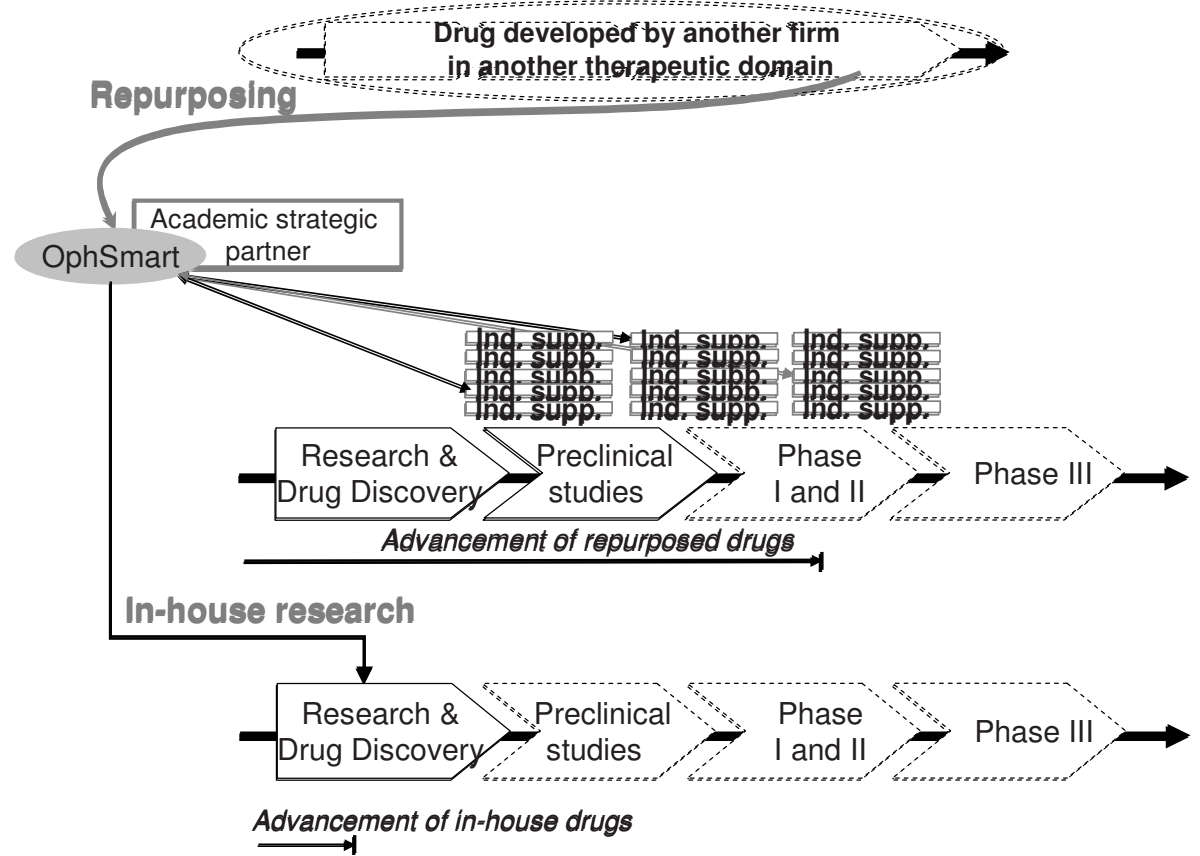

Figure 3: The network managed by OphSmart and position of actors on the value chain.

Most of the risks are supported by OphSmart. This inner management of risk is divided in two parts: a high risk with in-house research, but investments are low; and a low risk with the repurposing, with requires more funds because of the stages of developments. Actually risks of failure of the repurposed molecules are low because it has already shown safety and efficacy in other human applications.

Regarding value there is some similarities with Emics: no laboratories or manufacture capabilities, getting the best of competences in the network, choice of partner and long-run relationships. Over that, value created also comes from their skills in project management as well as a very deep understanding of the process of drug development. They manage a project with 6 persons where the pharmaceutical industry would need up to 150 . This performance comes from strong experiences and competences. OphSmart is not a place to start a carrier; it is a place to make the most of an experienced carrier. This is also valuable for the business part of OphSmart: the business model is very attractive for investors and the business developers are highly skilled in negotiation The process of development of repurposed drugs creates a lot of value: risks are low, developments are shortened because steps of toxicity and safety are very easy, and there is no fundamental research to do. As soon as they get the authorization they can start the preclinical phases and the pharmaceutical formulation. . Regarding value of in-house research, which could be perceived as a dead weigh by investors, it is on the contrary a positive signal. It is like a scientific guarantee. Organization is another point of value creation. The management team is very aware of methodology and management tools. As an example there is no reporting for the salaries: as OphSmart 
is small and informal in the way of management, nobody spends an hour in reporting.

Regarding the cost of repurposed drugs, there is the example of one of their molecule. They spent 15 million Euros in two years from preclinical studies to the end of phase I. The gap with big pharmas one is huge.

Oxpeckers are small birds that feed on insects which they pick from the backs of wild mammals like rhino. That illustrates the case of the repurposing firm that takes innovation from another bigger biotech or pharmaceutical company. It has a positive impact as unexpected revenue goes to the big pharma and an unexpected drug is developed for humankind. Meanwhile, the oxpecker find value for him: he has got bread and butter.

\section{DISCUSSION AND CONCLUSION}

These two case studies show that being virtual is possible in the European biopharmaceutical industry. The size and the prominence of a firm are not determining criteria to play the role of hub firm. Emics and OphSmart play successfully but differently this role. Regarding the knowledge mobility, enhanced in the concept of hub, information is shunted by the hub firms. It is more a selective sort than a wide delivery of information. The distribution of industrial property rights is different in both cases: Emics shares it with its strategic partners while OphSmart do it only under duress. Thus both firms attend to a right appropriation of innovation in accordance with the participation of each of actors. But networks are different (table 1). Emics lean on four strategic partners. This way the network is more solicited and involved in the vaccine development. On the opposite OphSmart is only backing on to its academic partner. The academic laboratory is one of the best in the world in the therapeutic domain of OphSmart. More than a simple collaboration there is also a strong commitment. The other actors of the network are less involved in the projects.

\begin{tabular}{|l|c|c|c|c|}
\hline Actors of the network & $\begin{array}{c}\text { Academic } \\
\text { strategic } \\
\text { partners }\end{array}$ & $\begin{array}{c}\text { Industrial } \\
\text { strategic } \\
\text { partners }\end{array}$ & $\begin{array}{c}\text { Academic } \\
\text { suppliers }\end{array}$ & $\begin{array}{c}\text { Industrial } \\
\text { suppliers }\end{array}$ \\
\hline Emics' network & 2 & 2 & 3 & 5 \\
\hline OphSmart's network & 1 & 0 & 0 & More than 18 \\
\hline
\end{tabular}

Table 1: Type and number of actors involved in the network of each firm

Both firms have a very light structure. Although they are virtual they keep a good control on the technological steps because they have a deep understanding of scientific issues. This is precisely a striking feature: the scientific team is a key for success in the complex environment of drugs. It appears to be easier for OphSmart to manage the value chain than for Emics because the scientific team is stronger and, more than the scientific level, they have experienced the process of drug development. It is in contradiction with Bamfield work for who virtual companies should use consultants and other outside agencies to advise on the various stages of the product development (Bamfield P. 2003). The scientific development is very complex and should be deeply understood by the virtual firm. Thus a virtual firm made of only venture capitalists would not be viable. 
But to be virtual implies the problem of credibility. Emics has difficulties to prove its credibility in front of other big pharmas and investors. OphSmart had to prove good skills in negotiation with suppliers: compared to big pharmas the bargaining power of virtual firms is small. When they want a supplier to do their study cheaply, quickly and before a study financed by a big Pharma, Emics and OphSmart showed high talents of negotiator. They do not have the same financial capabilities.

Regarding the repurposing, Chong and Sullivan (Chong C.R. and Sullivan D.J. Jr. 2007) basing their work on DiMasi et al.(DiMasi J.A., Hansen R.W. et al. 2003) corroborate our cost estimations: drug developers can bypass almost $40 \%$ of the overall cost of bringing a drug to market because toxicological and pharmacokinetic steps are easier. OphSmart as well as Emics have cost ten times inferior to the one announced by big pharmas. But these results should not be generalized. The issue of revenue model is also raised. Both firms are product based and expect to make profit when they will sell the product. The more a drug moves forward in a pipeline the more the value perceived is high.

Being virtual gave Emics and OphSmart more flexibility and access to the best of competences available. In both cases the management of the network is a success. However the situation is not so simple and developing a drug being virtual is fishing in troubled waters. We have not pointed out the issue of the market entry but we already know that in both case it is going to be very difficult and these companies should not do it by themselves. The destiny of biotech is still uncertain. In the eighties every body thought that it was going to change the face of the world and it did not (Hopkins M. M., Martin P.A. et al. 2007). Maybe this new way of organizing drug development will lead to a new way of doing business and keep biotech's initial promises.

\section{Acknowledgements}

We are grateful to management teams of both companies for permitting us to access to their data and for their willingness to give us details and long interviews. For helpful comments and suggestions we thank editors and anonymous reviewers.

Names of the firms have been changed in order to preserve confidentiality.

Bamfield P. (2003). The structural components of an R\&D organisation, Research and development management in the chemical and pharmaceutical industry, Wiley-VCH.

Chesbrough H.W. and Teece D.J. (1996). "Organizing for innovation: when is virtual virtuous? ." Harvard business review.

Chong C.R. and Sullivan D.J. Jr. (2007). "New uses for old drugs " Nature 448(9): 645-646.

Cooper W. and Muench M. (2000). "Virtual organizations: practice and the literature." Journal of organizational computing and electronic commerce 10(3): 189-208.

Dhanaraj C. and Parkhe A. (2006). "Orchestrating innovation networks." Academy of Management Review 31(3): 659-669.

DiMasi J. and Grabowski H.G. (2007). "The cost of biopharmaceutical R\&D: is biotech different?" Managerial and Decision Economics 28: 469-479.

DiMasi J.A., Hansen R.W., et al. (2003). "The price of innovation: new estimates of drug development cost,." Journal of Health Economics 22: 151-185.

Eisenhardt K. (1989). "Building theories from case study research." Academy of Management Review 14(4): 532-550.

Govindarajan V. and Gupta A.K. (2001). "Strategic innovation: a conceptual Road Map " Business Horizons: 3-12. 
Hopkins M. M., Martin P.A., et al. (2007). "The myth of biotech revolution: an assessment of technological, clinical and organisational change." Research policy 36(4): 566-589.

Lorenzoni G. and Baden-Fuller C. (1995). "Creating a strategic center to manage a web of partners." California Management Review 37(3): 146-163.

Magretta, J. (1998). "The power of virtual integration: an interview with Dell computer's." $\underline{\text { Havard }}$ business review: 73-84.

Mesquita L.F. (2007). "Starting over when the bickering never ends: rebuilding aggregate trust among clustered firms through trust facilitators " Academy of Management Review 32(1): 72-91.

Provan K.G. (1983). "The federation as an interorganizational linkage network " Academy of Management Review 8: 79-89

Rugman A. and D'Cruz J. (1997). "The theory of the flagship firm " European Management Journal 15(4): 403-412.

Sawhney M. and Parikh D. (2001). "Where values lives in a networked world." Harvard business review: 76-86.

Siggelkow N. (2007). "Persuasion with case studies." Academy of Management Journal 50(1): 20-24.

Weisenfeld U., Reeves J.C., et al. (2001). "Technology management and collaboration profile: virtual companies and industrial platforms in the high-tech biotechnology industries." R\&D Management 31(1): 91-100.

1 The Over the Counter Bulletin Board (OTCBB) is a quotation medium for subscribing members, not an issuer listing service and should not be confused with the Nasdaq Stock Market Inc. 